\title{
A Numerical Simulation of a Stationary Solar Field Augmented by Plane Reflectors: Optimum Design Parameters
}

\author{
Samer Yassin Alsadi ${ }^{1}$, Yasser Fathi Nassar ${ }^{2}$ \\ ${ }^{1}$ Electrical Engineering Department, Faculty of Engineering and Technology, Palestine Technical University-Kadoorie, Tulkarm, Palestine \\ ${ }^{2}$ Mechanical Engineering Department, Faculty of Engineering and Technology, Sebha University, Brack El-Shati, Libya \\ Email: samer_sadi@yahoo.com, yasser_nassar68@ymail.com
}

How to cite this paper: Alsadi, S.Y. and Nassar, Y.F. (2017) A Numerical Simulation of a Stationary Solar Field Augmented by Plane Reflectors: Optimum Design Parameters. Smart Grid and Renewable Energy, 8, 221-239.

https://doi.org/10.4236/sgre.2017.87015

Received: May 13, 2017

Accepted: July 3, 2017

Published: July 6, 2017

Copyright $\odot 2017$ by authors and Scientific Research Publishing Inc. This work is licensed under the Creative Commons Attribution International License (CC BY 4.0).

http://creativecommons.org/licenses/by/4.0/

\begin{abstract}
In this study, a theoretical analysis of a solar field augmented by a fixed reflector placed in the front between the top of the preceding row and the bottom of the succeeding row is presented. An analytical model has been developed and used to estimate the solar irradiation. The analytical model is based on the anisotropic sky model, assuming an infinite length of collector and reflector rows. A simulation has been carried out in order to figure out the behavior of the solar field and to find the optimum design parameters of the solar field leading to a maximum solar energy augmentation. The results obtained are depicted synoptically as a relationship between the solar field design parameters and the latitude angle, and this presentation enables us to determine the optimum design parameters in order to achieve the intended percentage improvement of solar radiation incident on the solar field rows at any location on the Northern hemisphere, which presents the novelty of this research. Also we have introduced a new parameter named "the effective height of the collector", which presents the portion of the collector's height illuminated by the reflector. This parameter is very important especially in case of PV solar fields, because it determines the domain of the concentrated solar energy over the surface of the PV panel.
\end{abstract}

\section{Keywords}

Plane Reflector, Solar Energy Augmentation, Solar Collector Effective Length, Solar Radiation, Solar Field

\section{Introduction}

Many concentrator types are possible for increasing the flux of radiation on receivers. They can be reflectors or refractors. They can be cylindrical to focus on a 
"line" or circular to focus on a "point". Receivers can be concave, flat or convex. Tubular absorbers with diffuse back reflector, tubular absorbers with specular cusp reflector, plane receiver with plane reflectors; parabolic concentrator; fresnel reflector; array of heliostats with central receiver are types of concentrating collector configurations. The simplest and most inexpensive means for increasing the solar energy flux incident onto a surface is to attach one or more planar reflectors to the main harvester system. Concentration devices can produce elevated operating temperature under clear sky conditions, but require good optical components, more precise construction techniques and generally a mechanism for tracking the sun. A reflector augmenting a collector is, however, the best solution at utilizing both diffuse and beam (direct) radiation, while providing a moderate concentration with minimal tracking [1]. The cost of the plane reflector is less than $5 \%$ of the cost of the PV system, while it can provide more than $15 \%$ yearly enhancement in solar energy collection inside soar energy devices. So, plane reflectors are very promising as an ideal method of improving the efficiency of PV modules with minor cost [2]. The feasibility for the addition of flat reflectors to PV panels is techno-economically investigated in [3] for various applications (building attached PVs, ground installations, grid-connected or standalone units), various constructions and various PV types (mono-crystalline and amorphous silicon PV panels). External reflectors have been analysed theoretically and in some works also experimentally for a single solar collector in literature [4] [5] [6] [7] [8]. Reflector in front of a collector is one of the options for improving the performance and cost-effectiveness of large collector fields. In solar fields the distance separating the rows has to be large to minimise shadowing effects early and late in the year. At high latitudes, a lot of solar radiation falling between the collector rows is not used in the summer. By introducing reflectors between the collector rows, most of this energy can be utilized by the collectors, reducing both the collector and land area requirements for a given load. Besides all these works the passivity side of reflector deployment in solar fields still under argumentation.

In this paper we present a modeling study of PV (photovoltaic) and/or thermal collectors with the aim of predicting the enhancement of the annual radiation harvested by a solar collector due to matching with the reflective surface, mounted diagonally between two adjacent rows. In this regards we have performed a theoretical analysis on a tilted collector and reflector system in order to determine the optimal angle of collectors corresponding to a specific solar field's design parameters and for any location on the Northern hemisphere. A cross section of a collector array with reflectors is shown in Figure 1.

We normally choose a tilt angle for solar collectors and plane reflectors in solar field installations, this increases the energy yield and decreases the losses due to collector and reflector dirtying compared to horizontal systems. Practically the reflector may be divided into two parts in such manner, that the upper part of the reflector $\left(L_{r, \text { upper }}\right)$ is equal to the collector projection on the vertical plane ( $L_{r, \text { upper }} \cong L_{c} \sin S_{c}$ ), so the reflector can plait in order to allow technicians to pass 


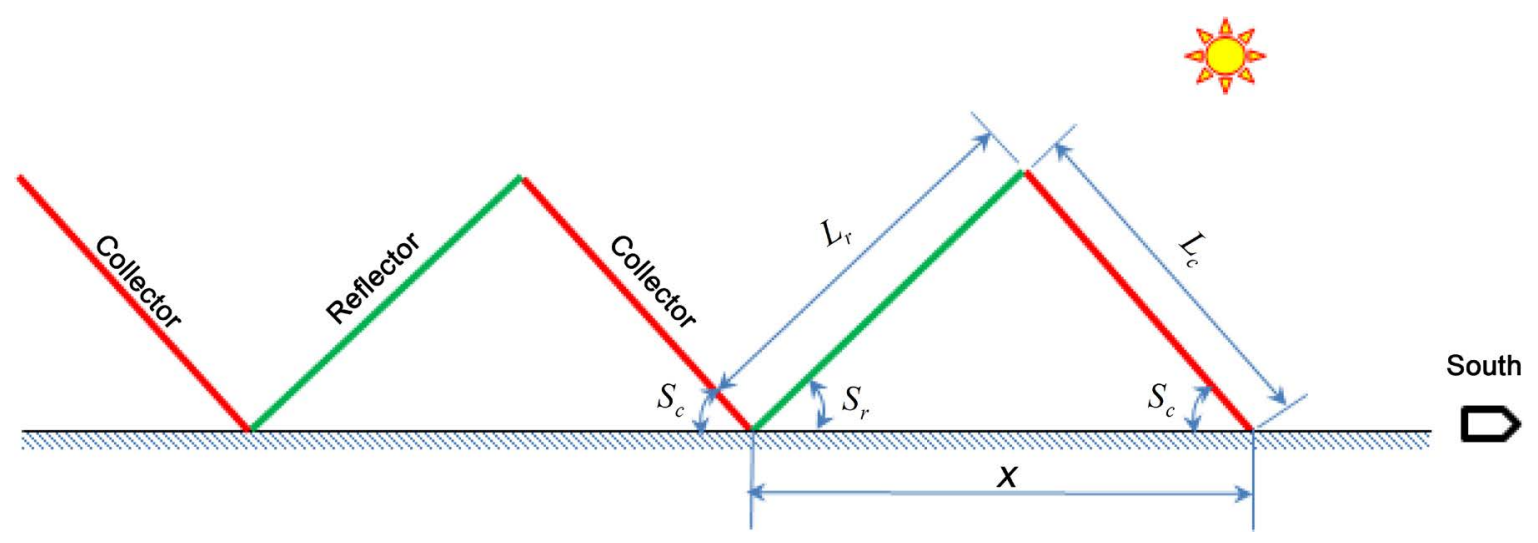

Figure 1. Deployment of stationary solar collector arrays with plane reflectors on a solar field.

through the space between the rows for cleaning or maintenance purposes. The shadow is not involved in this study because the reflector is not shadow causative in this arrangement, according to the study assumptions.

\section{Solar Radiation on a Single Tilted Surface}

For purposes of solar process design and performance calculations, it is often necessary to calculate the hourly radiation on a tilted surface. There are many models and softwares developed and utilized by researchers to estimate solar irradiance and PV-array performance in solar fields. The National Renewable Energy Laboratory System Advisor Model (SAM) is used four radiation models included in the TRNSYS radiation processor within SAM: Perez, Hay \& Davies, Reindl, and isotropic sky. While in the EnergyPro is used the Reindl model.

The model considers the anisotropy diffuse sky model formulated by Hay and Davis [9]. This model is suitable for clear conditions, and most of the diffuse will be assumed to be forward scattered [10]. It includes components of beam directly from the sun and diffuse irradiation from the circumsolar and the sky dome, and beam and diffuse irradiation reflected from the ground. The total solar radiation $\left(I_{s, T}^{t}\right)$ on a tilted surface at slope $\left(S_{s}\right)$ from the horizontal for an hour as the sum of three components is given as:

$$
\begin{aligned}
& I_{s, T}^{t}=\left(I_{b}^{t}+I_{d, c s}^{t}\right) R_{b, s}^{t}+I_{d, i s o}^{t} F_{s-s k y}+\left(I_{b}^{t}+I_{d, c s}^{t}+I_{d, i s o}^{t}\right) \varrho_{g} F_{s-g} \\
& I_{s, T}^{t}=\left(I_{b}^{t}+A_{i}^{t} I_{d}^{t}\right) R_{b, s}^{t}+\left(1-A_{i}^{t}\right) I_{d}^{t} F_{s-s k y}+\left(I_{b}^{t}+I_{d}^{t}\right) \varrho_{g} F_{s-g},\left[\mathrm{~W} / \mathrm{m}^{2}\right]
\end{aligned}
$$

where $I_{b}^{t}$ is the hourly beam radiation from the sun on a horizontal surface, $I_{d, c s}^{t}$ and $I_{d, i s o}^{t}$ are the hourly diffuse radiation parts of the circumsolar and the isotropic on a horizontal surface, so the total diffuse radiation on a horizontal surface will be equal to the sum of these two components $I_{d}^{t}=I_{d, c s}^{t}+I_{d, \text { iso }}^{t}$, having neglected the horizon brightening diffuse radiation component, according to Hay and Davis anisotropic sky model. The circumsolar component can be expressed as: $I_{d, c s}^{t}=A_{i}^{t} I_{d}^{t}$, in where $A_{i}^{t}$ is the anisotropic index which is a function of the transmittance of the atmosphere for beam radiation and then $A_{i}^{t}=\frac{I_{b}^{t}}{I_{o}^{t}}$, where $I_{o}^{t}$ is the hourly extraterrestrial radiation on a horizontal sur- 
face [9], which equal to:

$$
I_{o}^{t}=G_{s c}\left(1+0.033 \frac{360 n}{365}\right) \cos \theta_{z}^{t},\left[\mathrm{~W} / \mathrm{m}^{2}\right]
$$

where $G_{s c}$ is the solar constant $\left(1367 \mathrm{~W} / \mathrm{m}^{2}\right), n$ is denotes to day of the year, and $\theta_{z}^{t}$ is the solar zenith angle at the time and day of interest.

The $R_{b, s}^{t}$ is a geometric factor which presents the ratio of beam radiation on the tilted surface to that on a horizontal surface at any time, $R_{b, s}^{t}=\frac{\cos \theta_{i, s}^{t}}{\cos \theta_{z}^{t}}$ in where $\theta_{i, s}^{t}$ is the solar incident angle and calculated from the following equation [9], with the corresponding azimuth surface angle $\psi_{s}$ and tilt angle $S_{s}$ :

$$
\theta_{i, s}^{t}=\cos ^{-1}\left[\sin S_{s} \cos \theta_{z}^{t} \cos \left(\phi^{t}-\psi_{s}\right)+\cos S_{s} \sin \theta_{z}^{t}\right]
$$

and $\theta_{z}^{t}$, is the solar zenith angle; and $\phi^{t}$, is the solar azimuth angle.

$$
\begin{aligned}
\theta_{z}^{t} & =\cos ^{-1}[\sin \delta \sin L+\cos \delta \cos L \cos h] \\
\phi^{t} & =\cos ^{-1}\left[\frac{\sin \delta \cos L-\cos \delta \sin L \cos h}{\sin \theta_{z}^{t}}\right]
\end{aligned}
$$

where: $L$ denotes the local latitude, angle $\delta$ is the declination angle, and $h$ is the hour angle: $h=15\left(t_{s}-12.0\right)$ in where $t_{s}$ presents the solar time. And $\varrho_{g}$ is the ground-reflectivity, $F_{s-s k y}$ and $F_{s-g}$ are the collector-sky and collector-ground view factor, respectively. For a single tilted surface, the view factors are [10]:

$$
\begin{aligned}
& F_{s-s k y}=\frac{1+\cos S_{s}}{2} \\
& F_{s-g}=\frac{1-\cos S_{s}}{2}
\end{aligned}
$$

In this paper, the ASHRAE clear-sky model is adopted to estimate the hourly beam normal $\left(I_{b n}^{t}\right)$ and diffuse $\left(I_{d}^{t}\right)$ solar radiation. The ASHRAE clear-sky model appears to be general enough for the objective of the paper; furthermore, we don't need to any information about the location of interest, except for the latitude angle.

The direct beam radiation and sky diffuse are calculated from the following formula [11]:

$$
\begin{aligned}
& I_{b n}^{t}=A \mathrm{e}^{\frac{-B}{\cos \theta_{z}^{t}}} \\
& I_{b}^{t}=I_{b n}^{t} \cos \theta_{z}^{t} \\
& I_{d}^{t}=C I_{b n}^{t}
\end{aligned}
$$

where $A, B$ and $C$ are constants for every day and are given in Table 1 for the $21^{\text {st }}$ day of each month [11].

The optimum tilt angle had been early calculated in [12] and was found as:

$$
S_{s, o p t}=1.5+1.35 L-0.01069 L^{2}
$$

The annual solar radiation incident on a single tilted surface has been calcu- 
Table 1. Constants for ASHRAE equations for the $21^{\text {st }}$ day of each month.

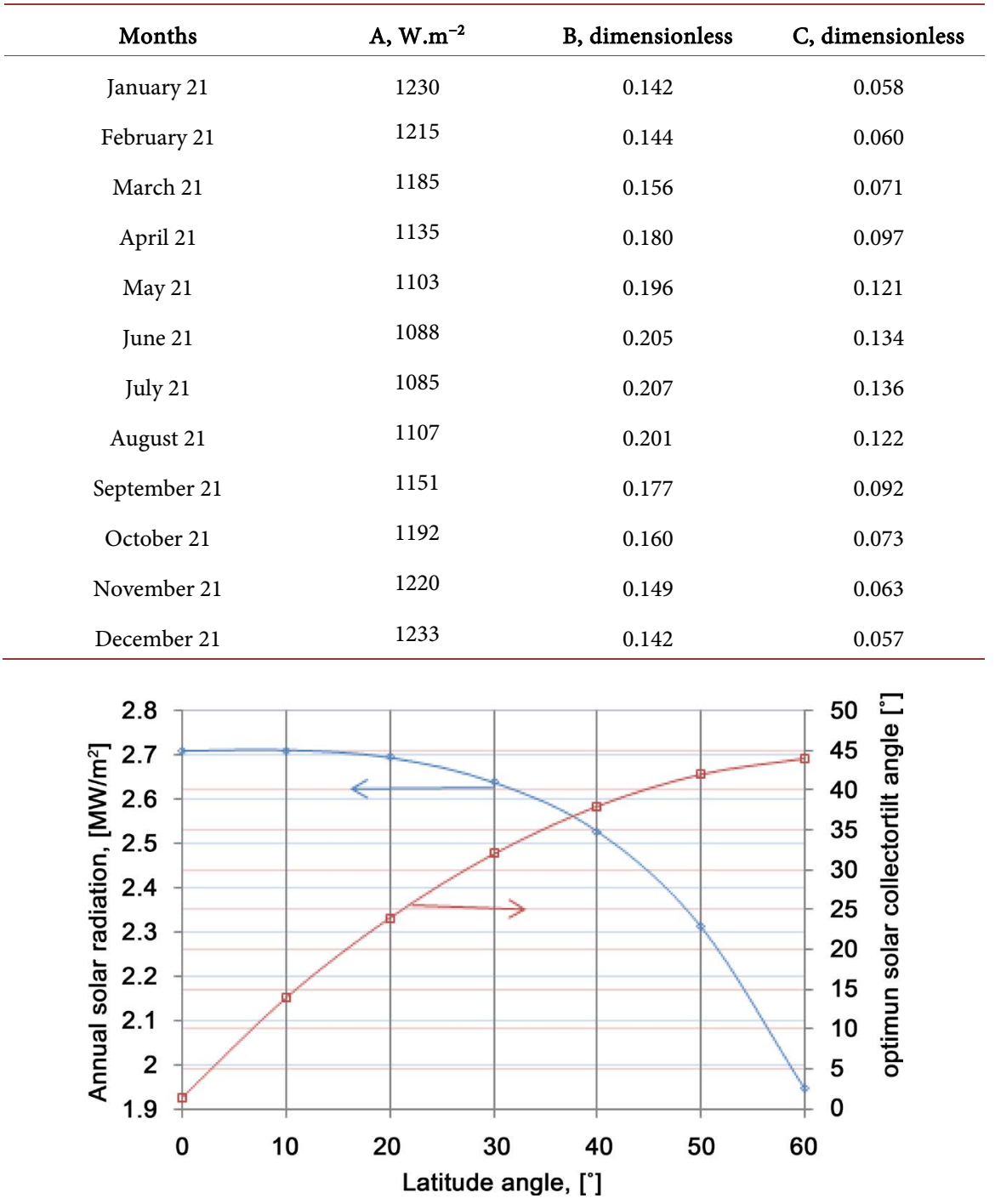

Figure 2. The optimum surface tilted angle and the corresponding annual solar radiation vs. latitude angle.

lated for comparison purpose. Figure 2 illustrates the optimum surface tilted angle and the corresponding annual solar radiation for various latitudes on the Northern hemisphere.

\section{Geometry of the System}

The flat concentrator system to which we will refer, to quantify the amount of radiation incident on the collector is extended diagonally from the top of the preceding row to the bottom of the succeeding row as it illustrated in Figure 1. A cross-section of one row is depicted schematically in Figure 3, in where all the dimensions which we need for the simulation are presented for the collector-reflector system.

The values of the reflector height to the collector height ratio $\left(\frac{L_{r}}{L_{c}}\right)$ and the 


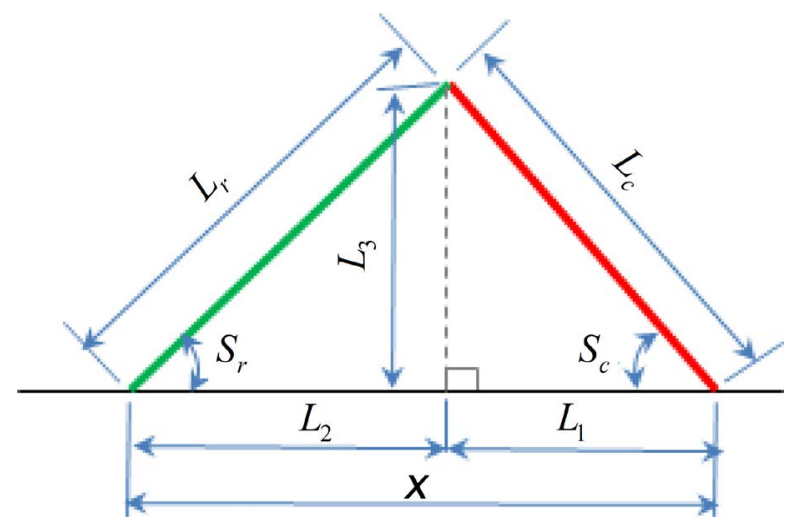

Figure 3. Side view of one collector-reflector row, where: $L_{1}=L_{c} \cos S_{c}$, $L_{2}=X-L_{c} \cos S_{c}, L_{3}=L_{c} \sin S_{c}, S_{r}=\tan ^{-1}\left(\frac{L_{3}}{L_{2}}\right)$, and $L_{r}=\frac{L_{3}}{\sin S_{r}}$.

reflector tilted angle $\left(S_{r}\right)$ are calculated according to the field design parameters: $\left(S_{c}, \frac{X}{L_{c}}\right)$ the collector tilted angle, and distance separating the rows to the collector height ratio, respectively. According to Figure 3, the reflector tilt angle is given by the following formula:

$$
S_{r}=\tan ^{-1}\left[\frac{\sin S_{c}}{\frac{X}{L_{c}}-\cos S_{c}}\right]
$$

And, the reflector to collector height ratio is calculated from the following formula:

$$
\frac{L_{r}}{L_{c}}=\frac{\sin S_{c}}{\sin S_{r}}
$$

The variation of the reflector parameters $\left(S_{r}, \frac{L_{r}}{L_{c}}\right)$ with respect to the solar field parameters $\left(S_{c}, \frac{X}{L_{c}}\right)$ is calculated and plotted in Figure 4.

\section{Modeling of Solar Radiation in Solar Fields Augmented by Plane Reflectors}

Principally, the approach discussed herewith is based on the following assumptions:

1) The analysis is 2-D. This means no irradiance from the reflector is falling away from the sides of the collector, this assumption is acceptable for multi-rows large solar fields with very long length of the collector and reflector;

2) The sky-diffuse irradiation is assumed to be anisotropic, and is determined by using view factors presented in a previous work [13], for both the collector and the reflector; 


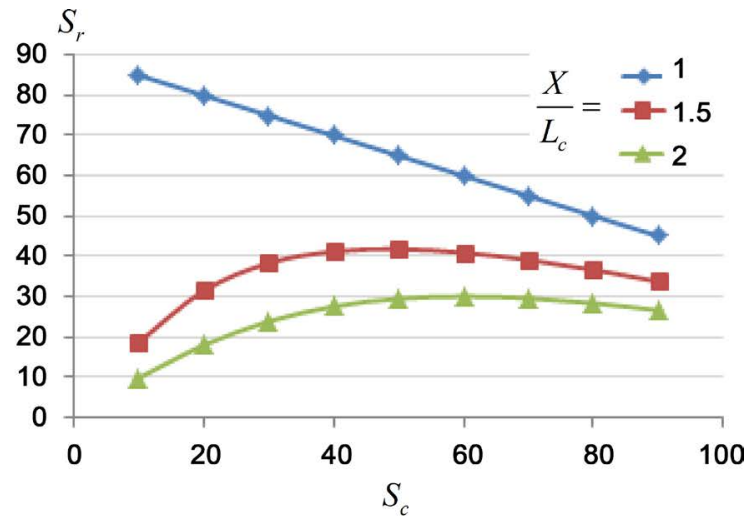

(a)

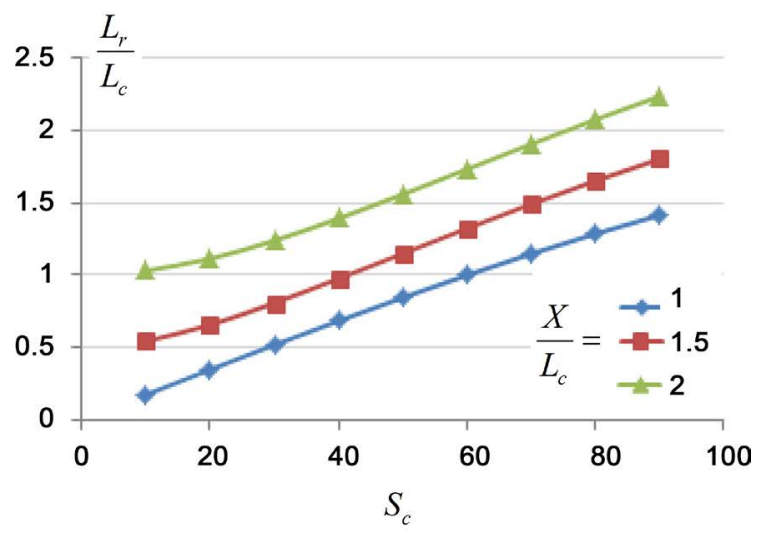

(b)

Figure 4. The values of the reflector design parameters (a): $\left(S_{r}\right)$ and (b): $\left(\frac{L_{r}}{L_{c}}\right)$, as a function of the solar field design parameters $\left(S_{c}, \frac{X}{L_{c}}\right)$.

3) The reflector surface is considered fully polished and therefore, the incident angle and reflect angle of the sunray are the same;

4) The collector is able to see only the sky and the reflector surface;

5) When the effective length ratio is greater than 5 the reflected rays considered parallel to the collector plane;

6) The collector and reflector surfaces are always illuminating and there is no shadowing effect;

7) The reflectivity of the reflector surface is constant and independent on the solar incidence angle.

The model considers the anisotropic diffuse sky model, which includes components of beam, diffuse irradiation, and beam and diffuse irradiation reflected from the reflector, as it depicted in Figure 5. The collectors are south facing $\left(\psi_{c}=0^{\circ}\right)$ and the reflectors are north facing $\left(\psi_{r}=180^{\circ}\right)$. The configuration is considered to be of infinite length and with variable solar field design parameters $\left(S_{c}, \frac{X}{L_{c}}\right)$. Treating the beam components by the corresponding incident 


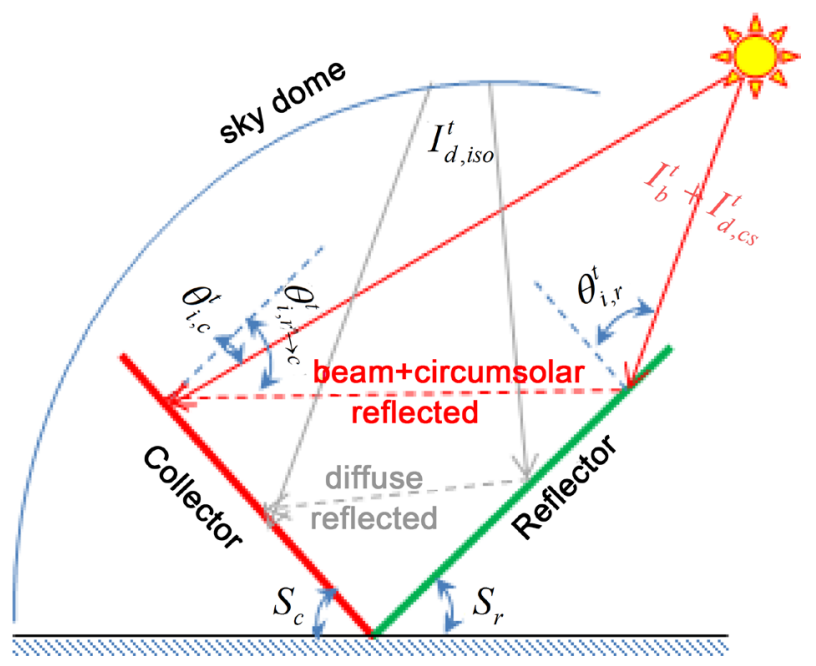

Figure 5. Solar radiation components and the three solar incident angles.

angles and the diffuse components by the corresponding view factors, the summation of them will be the total solar radiation incident on the collector. Now our aim is to calculate the following:

1) The solar incident angles;

2) The view factors; and

3) The beam and sky-diffuse solar radiation components.

\subsection{The Solar Incident Angles}

There are only four independent variables for the solar field; the first two are the solar field design parameters $\left(S_{c}, \frac{X}{L_{c}}\right)$, the third is the location (latitude), and the fourth independent variable is, of course, the time represented in solar angles. From our point of view, the incident solar angle represents the connection between the solar field design parameter and the position of the sun in the sky, and it will be a good indicator for analysing the problem, for this reason we choose the incident solar angle instead of solar altitude angle which adopted by others.

There are three incidence angles in this arrangement, those are:

1) Incident angle from the sun to the reflector $\left(\theta_{i, r}^{t}\right)$;

2) Incident angle from the reflector onto the collector $\left(\theta_{i, r \rightarrow c}^{t}\right)$; and

3) Incident angle from the sun to the collector $\left(\theta_{i, c}^{t}\right)$.

The solar incident angles $\theta_{i, r}^{t}$ and $\theta_{i, c}^{t}$ are calculated from Equation (3) with the corresponding $\left(\psi_{r}, S_{r}\right)$ and $\left(\psi_{c}, S_{c}\right)$ for the reflector and the collector respectively, at the time and the location of interest. Accordingly $\left(\theta_{i, r \rightarrow c}^{t}\right)$ is calculated from Figure 10 below:

$$
\theta_{i, r \rightarrow c}^{t}=90^{\circ}-\theta_{3}^{t}
$$

The incident angles have been calculated for Brack-Libya $\left(L=27.53^{\circ} \mathrm{N}\right)$ at solar-noon for spring equinox, and for summer and winter solstices as a function of the solar-field design parameters and plotted in contour manner in Figure 6, Figure 7, and Figure 8. As presented in the Figure 6, the incident angle of the 


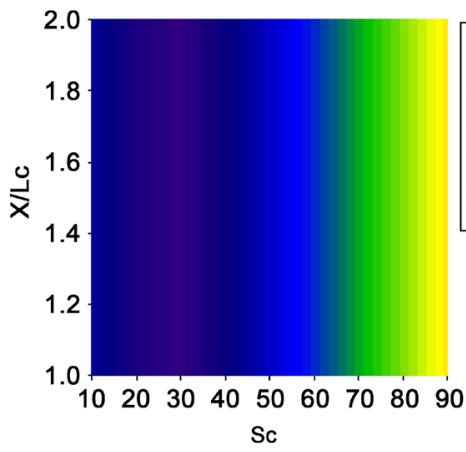

Spring equinox
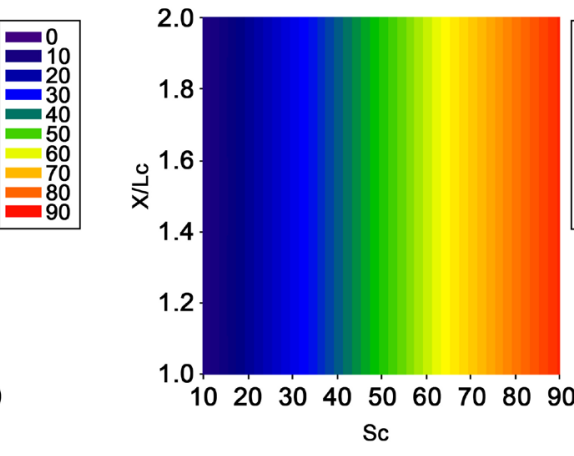

Summer solstice

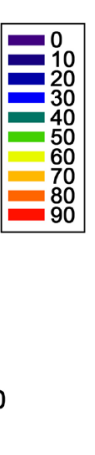

Figure 6. The solar incident angle on the collector surface $\left(\theta_{i, c}^{t}\right)$.
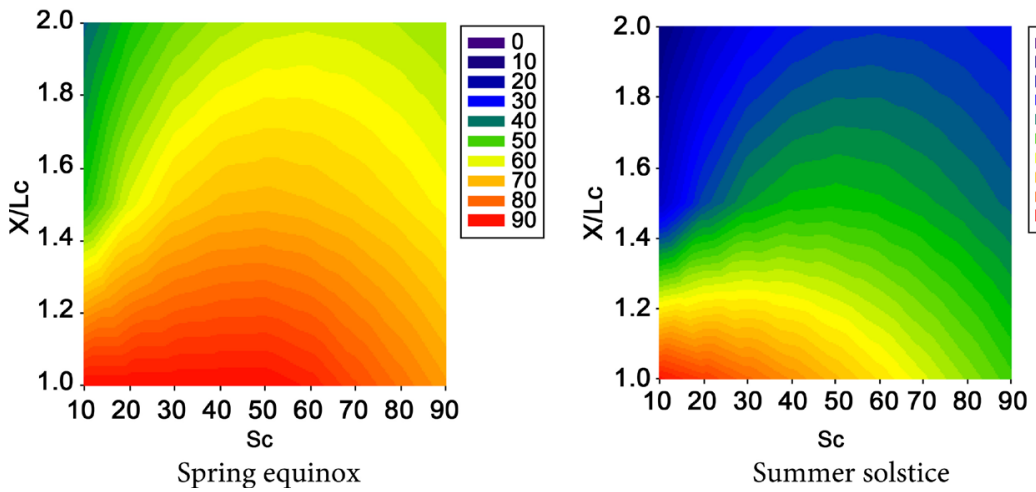

Figure 7. The solar incident angle on the reflector surface $\left(\theta_{i, r}^{t}\right)$.
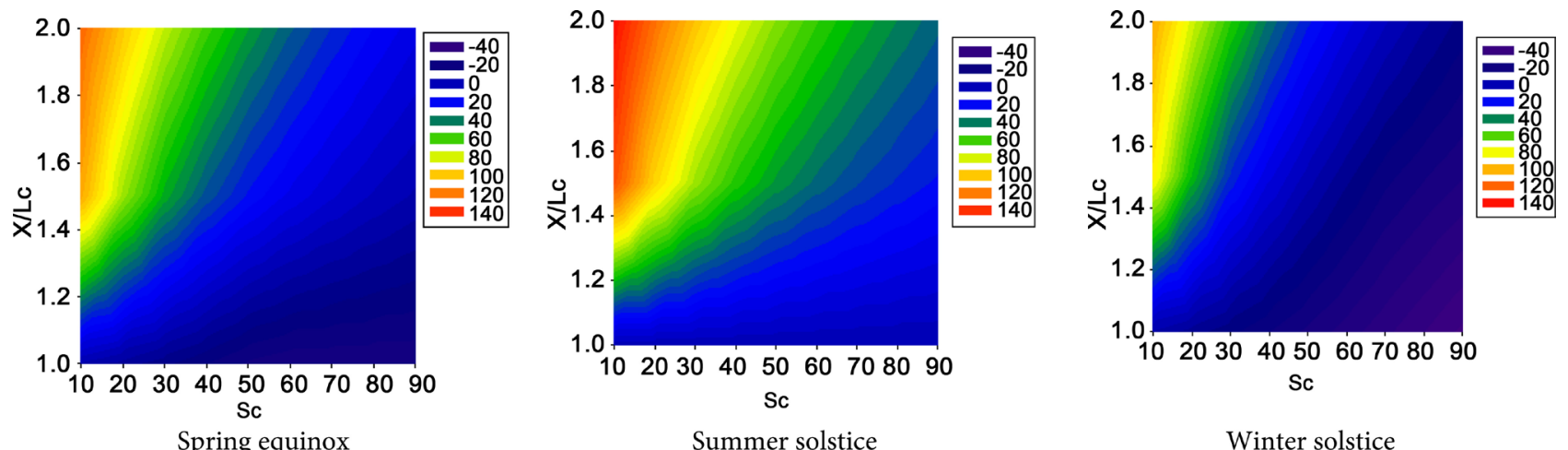

Winter solstice

Figure 8. The reflected solar incident angle from the reflector on the collector surface $\left(\theta_{i, r \rightarrow c}^{t}\right)$.

collector $\theta_{i, c}^{t}$ is independent on the distance ratio $\left(\frac{X}{L_{c}}\right)$ but depends only on the collector tilt angle $S_{c}$. While, the incident angle of the reflector $\theta_{i, r}^{t}$ depends on both parameters $\frac{X}{L_{c}}$ and $S_{c}$, because the reflector tilted angle itself depends on $\frac{X}{L_{c}}$ and $S_{c}$, and so the incident angle from the reflector onto the collector $\left(\theta_{i, r \rightarrow c}^{t}\right)$.

All incident angles range $\left[0^{\circ}, 90^{\circ}\right]$, in case of the reflected incident angle be- 
longs to $\left(\theta_{i, r \rightarrow c}^{t} \leq 0^{\circ}\right)$ or $\left(\theta_{i, r \rightarrow c}^{t} \geq 90^{\circ}\right)$ the collector interested by the beam and diffuse components from the sun and the sky direct to the collector and the isotropic sky-diffuse reflected from the reflector only, because there are neither beam nor circumsolar incident on the reflector surface. Consequently the effective height ratio is set to be zero.

\subsection{View Factors Calculations}

Sky view factors for both the collector and the reflector are calculating according to [13]. The equations are rearranged in terms of dimensionless parameters. The collector-sky view factor $F_{c-s k y}$ and the reflector-sky view factor $F_{r-s k y}$ are rewritten in the following forms:

$$
\begin{gathered}
F_{c-s k y}=0.5\left[1+\frac{X}{L_{c}}-\sqrt{1+\left(\frac{X}{L_{c}}\right)^{2}-2 \frac{X}{L_{c}} \cos S_{s}}\right] \\
F_{r-s k y}=\frac{\left[\frac{L_{r}}{L_{c}}+\frac{X}{L_{c}}-\sqrt{\left(\frac{L_{r}}{L_{c}}\right)^{2}+\left(\frac{X}{L_{c}}\right)^{2}-2 \frac{X}{L_{c}} \frac{L_{r}}{L_{c}} \cos S_{r}}\right]}{2 \frac{L_{r}}{L_{c}}}
\end{gathered}
$$

Using the view factor algebra the collector-reflector view factor is:

$$
F_{c-r}=1-F_{c-s k y}
$$

\section{Dynamic Analysis of the Collector and the Reflector}

Due to the continued change of the sun position on the sky, therefore, the solar radiation geometry is also changing. In this manner, we introduce five possible cases for the situation of the reflected beam irradiance from the reflector to the collector according to the concentration level. Accordingly, we illustrate the five cases graphically in Figure 9. In where:

a) Zero concentration: when the reflector is blocked by the shadow of the previous row.

b) Nonhomogeneous high-concentration: when all beam radiation incident on the reflector is reflected to a portion of the collector.

c) Homogeneous normal-concentration: when all beam radiation incident on the reflector is reflected to the entire collector without any losses.

d) Homogeneous low-concentration: when only a fraction of the beam radiation incident on the reflector is reflected to the entire collector with some radiation missing outside the collector.

e) Zero concentration: when the reflected beam radiation from the reflector is parallel to the collector's plane.

Figure 10 illustrates the dynamic analysis of all angles affecting the solar radiation incident directly from the sun on both surfaces of the collector and the reflector and reflected irradiance from the reflector to the collector. The diffuse-sky irradiances and its reflected component are independent of these angles. 


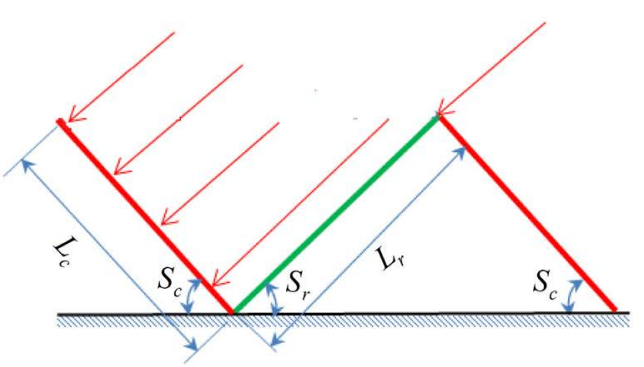

(a)

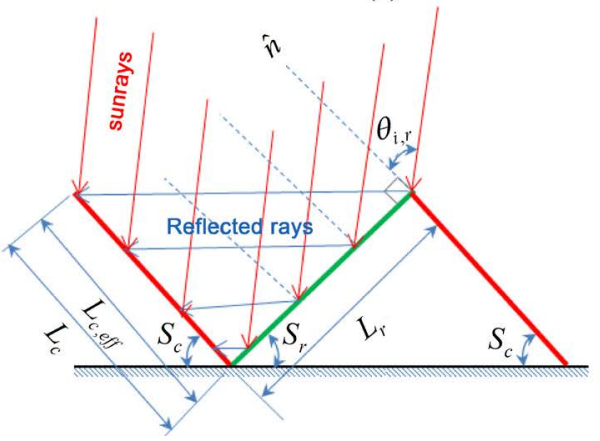

(c)

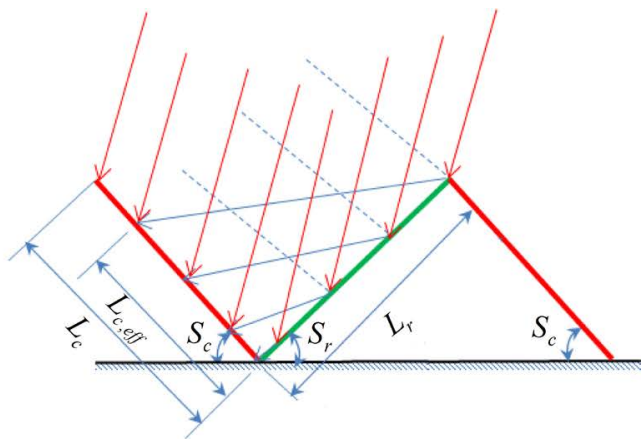

(b)

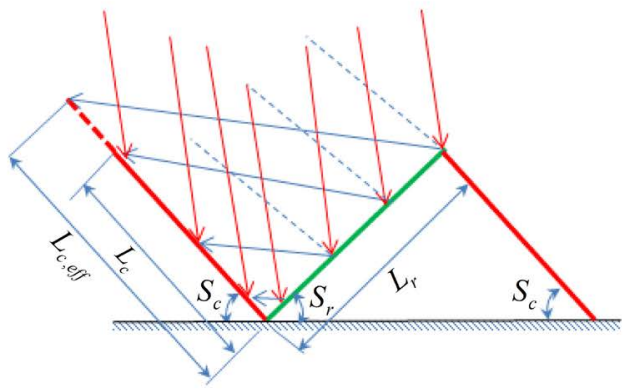

(d)

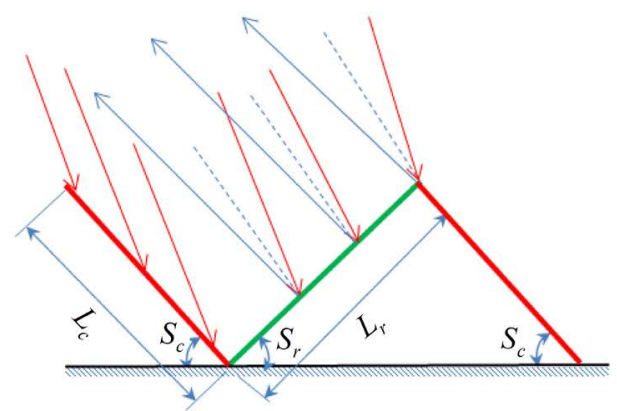

(e)

Figure 9. The five basic situations of incidence beam solar radiation onto the reflector and the collector (red arrows), and reflected from the reflector onto the collector (blue arrows).

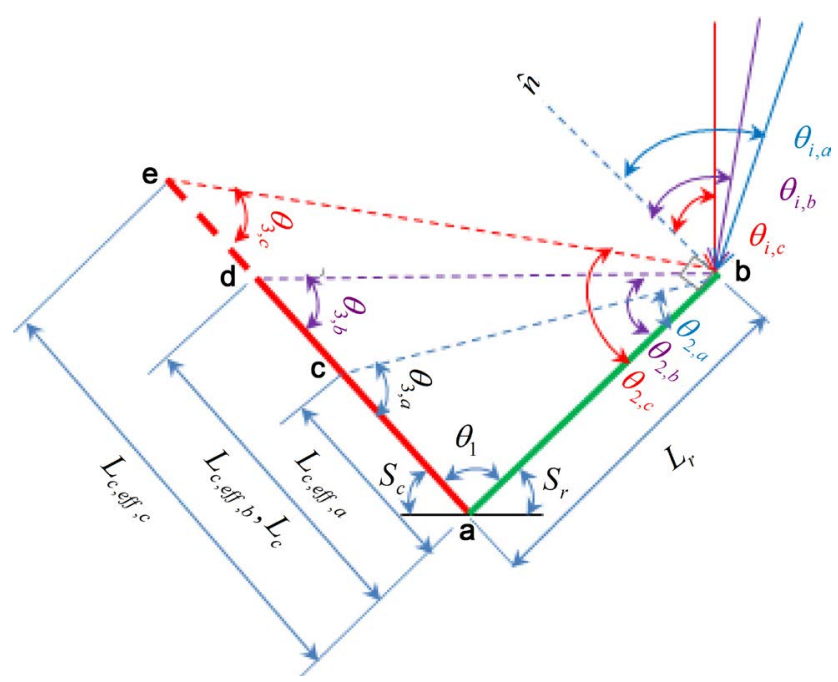

Figure 10. The problem statement. 
However, they are dependent on the view factors of the reflector-sky, collector-sky and collector-reflector view factors.

Knowing the solar incident angle on the reflector $\theta_{i, r}^{t}$, which is a function of the time, day and the latitude, and according to Figure 5, one can determine the angles illustrated in Figure 10 from the following formulas:

$$
\begin{aligned}
& \theta_{1}=180^{\circ}-S_{c}-S_{r}, \theta_{2}^{t}=90^{\circ}-\theta_{i, r}^{t} \\
& \text { and } \theta_{3}^{t}=180^{\circ}-\theta_{1}-\theta_{2}^{t}
\end{aligned}
$$

where $t$ is the time, which presents the dynamic situation of the problem.

As regards the treatment of the problem we introduce a new quantity named "effective collector height ratio $\left(\frac{L_{c, e f f}^{t}}{L_{c}}\right)$ ". This quantity is an essential indicator for classifying the operation regime of the collector. This parameter indicates to the collector portion that is illuminated by the reflected irradiance from the reflector, and it is expressed as a dimensionless in the form:

$$
\frac{L_{c, e f f}^{t}}{L_{c}}=\frac{L_{r}}{L_{c}} \frac{\sin \theta_{2}^{t}}{\sin \theta_{3}^{t}}
$$

In this context, this parameter is considered as a tool to determine the solar energy situation of the collector-reflector system. Table 2 shows these situations according to the effective collector height ratio.

Figure 11 presents the variation of the effective height ratio $\frac{L_{c, \text { eff }}^{12: 00}}{L_{c}}$ with time, as a function of the solar field design parameters $\frac{X}{L_{c}}$ and $S_{c}$ for the spring equinox, summer and winter solstices, at the solar-noon for latitude of $27^{\circ}$.

Analysing Figure 11 in conjunction with Figure 4 and Figure 10, one can realize that curves can be divided into two parts, the first one is, for $\frac{X}{L_{c}}=1.5$ and

Table 2. Classification of the solar collector situation according to the effective collector height ratio $\left(\frac{L_{c, e f f}^{t}}{L_{c}}\right)$.

\begin{tabular}{ccc}
\hline Situation of & Case & Illustration \\
\hline$\frac{L_{c, \text { eff }}^{t}}{L_{c}} \leq 0$ & A & zero concentration (shading from the previous row) \\
$0<\frac{L_{c, \text { eff }}^{t}}{L_{c}}<1$ & B & honhomogeneous high concentration \\
$\frac{L_{c, \text { eff }}^{t}}{L_{c}}=1$ & $\mathrm{C}$ & homogeneous low-concentration \\
$\frac{L_{c, \text { eff }}^{t}}{L_{c}}>1$ & $\mathrm{D}$ & \\
$\frac{L_{c, \text { eff }}^{t}}{L_{c}} \gg 1$ & $\mathrm{E}$ & zero concentration (reflected irradiance parallel to the collector plane)
\end{tabular}



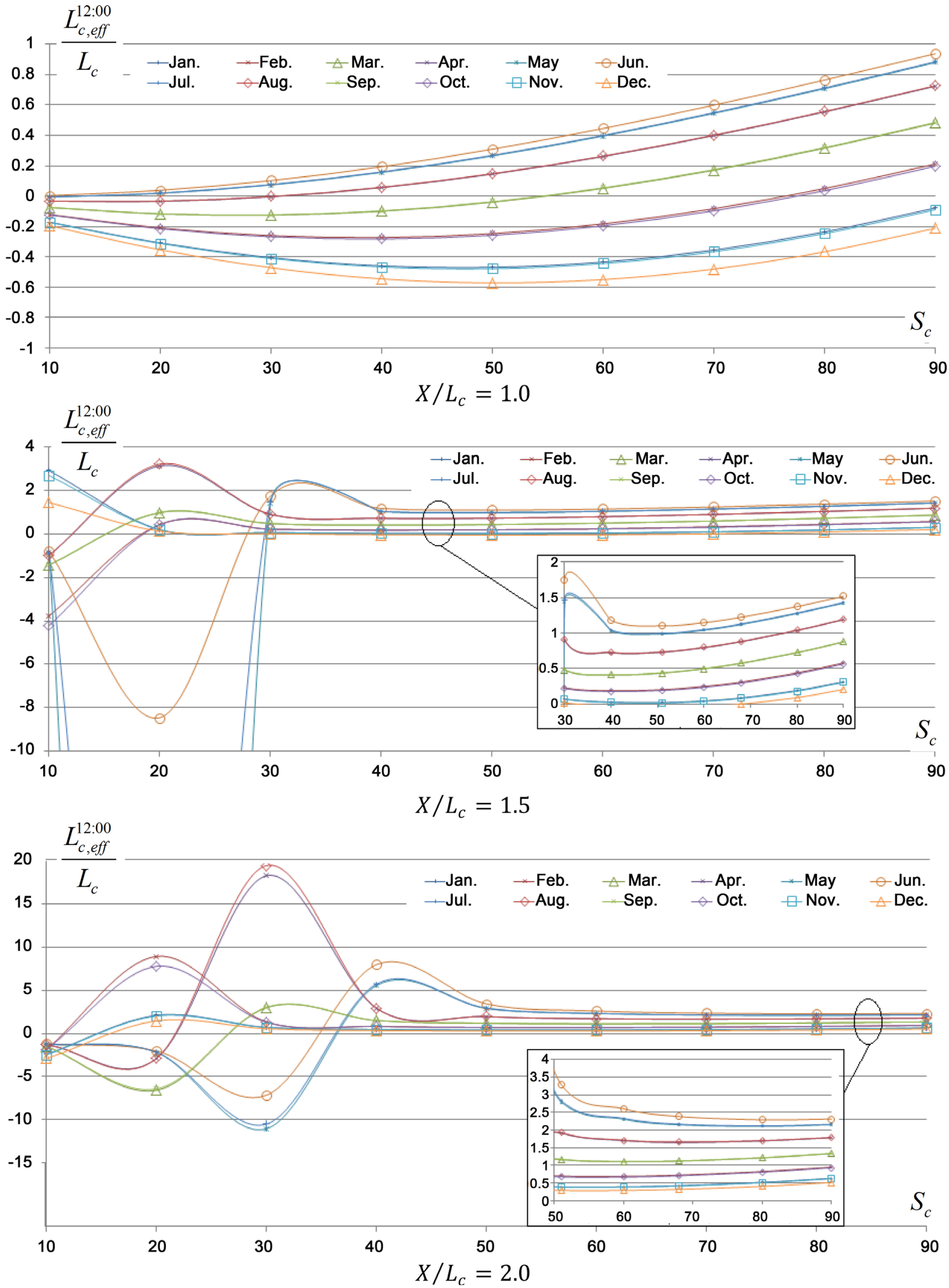

Figure 11. Effective height ratio at solar-noon as a function of the solar field design parameters for the day $21^{\text {st }}$ of every month, for latitude of $27.53^{\circ} \mathrm{N}$. 
2.0 when the collector tilt angle $S_{c} \leq 40^{\circ}$, the reflector tilt angle $S_{r}$ is increasing with increasing $S_{c}$, when the sun is far away on the southern hemisphere in winter season, beginnings of spring and autumn ends the incident angle $\theta_{i, r}^{t}$ on the reflector is wide this leads to increase the value of the angle $\theta_{2}^{t}$ accordingly the value of $\theta_{3}^{t}$ is growing then we get a positive values for the effective height ratio $\frac{L_{c, e f f}^{t}}{L_{c}} \geq 0$, vice versa for the summer season. With the same manner for the rest region of $S_{c}>40^{\circ}$, the value of $S_{r}$ is decreasing with increasing of $S_{c}$ this leads to increase the value of the $\theta_{i, r}^{t}$ this will increase the opportunity of the positive values for the effective height ratio $\frac{L_{c, e f f}^{t}}{L_{c}} \geq 0$.

Since all angles and view factors are determined, it is now possible to estimate the solar radiation incident on the reflector and the collector.

\section{Solar Radiation Components Calculation}

According to the above mentioned analysis, the definition of all irradiances $\left(I_{c, T}^{t}\right)$ that strike the collector's surface, may be expressed as:

$I_{c, T}^{t}=\left(I_{b}^{t}+A_{i}^{t} I_{d}^{t}\right)\left[R_{b, c}^{t}+\frac{L_{r}}{L_{c}} \frac{L_{c, e f f}^{t}}{L_{c}} \varrho_{r} R_{b, r \rightarrow c}^{t}\right]+\left(1-A_{i}^{t}\right) I_{d}^{t}\left[F_{c-s k y}+\frac{L_{r}}{L_{c}} \varrho_{r} F_{r-s k y} F_{c-r}\right]$ (17)

where: the geometric factors $R_{b, c}^{t}=\frac{\cos \theta_{i, c}^{t}}{\cos \theta_{z}^{t}}$ and $R_{b, r \rightarrow c}^{t}=\frac{\cos \theta_{i, r \rightarrow c}^{t}}{\cos \theta_{z}^{t}}$, and $\varrho_{r}$ is the reflectivity of the reflector.

In cases (A and $\mathrm{E}$ ) the ratio $\left(\frac{L_{c, e f f}^{t}}{L_{c}}\right)$ is set to be zero, which means the collector has not be received reflected beam and circumsolar irradiation and it has be received only isotropic diffuse from the reflector.

\section{Results and Discussion}

An MsExcel sheet has been prepared in order to calculate all variables involving in the simulation process. Table 3 presents the input variables and their values.

Table 3. The input parameters and variables included in the MsExcel sheet.

\begin{tabular}{cc} 
Parameter or variable & Value \\
\hline Latitude angle, $L$ & $27^{\circ} \mathrm{N}$ \\
Optimum single surface tilted angle (reference) & $30^{\circ}$ \\
Distance separating ratio, $X / L_{c}$ & $1.0,1.5$, and 2.0 \\
Solar collector tilt angle, $S_{c}$ & $10^{\circ}, 20^{\circ}, \ldots, 90^{\circ}$ \\
Ground reflectivity, $\varrho_{g}$ & 0.5 \\
Reflector reflectivity, $\varrho_{r}$ & 0.9 \\
Collector azimuth angle, $\psi_{c}$ & $0^{\circ}$ (south facing) \\
Reflector azimuth angle, $\psi_{r}$ & $180^{\circ}$ (north facing) \\
\hline
\end{tabular}


The results have been obtained for a site (Brack -Libya) locates on latitude angle of $27.53^{\circ} \mathrm{N}$ and longitude angle of $14.28^{\circ} \mathrm{E}$.

Applying Equation (17) to calculate the total solar radiation incident on the collector, the results obtained were plotted in Figure 12. The solar field design parameter $\left(S_{c}, \frac{X}{L_{c}}\right)$ have been varied in order to see the effect of these parameters on the performance of the solar field that employed reflectors. Figure 12 shows the theoretical predictions of the hourly variations of the total solar radiation incident on the solar collector employed plane reflector for Brack El-Shati site at spring equinox and the solstices with distance ratio $\frac{X}{L_{c}}=1,1.5$, and 2 [m]. The behaviour of the solar incident angle $\left(\cos \theta_{i, r}^{t}\right)$ on the reflector presents the key for understanding the process. When $\left(\theta_{i, r}^{t}\right)$ is large (see Figure 7$)$ and

Spring equinox
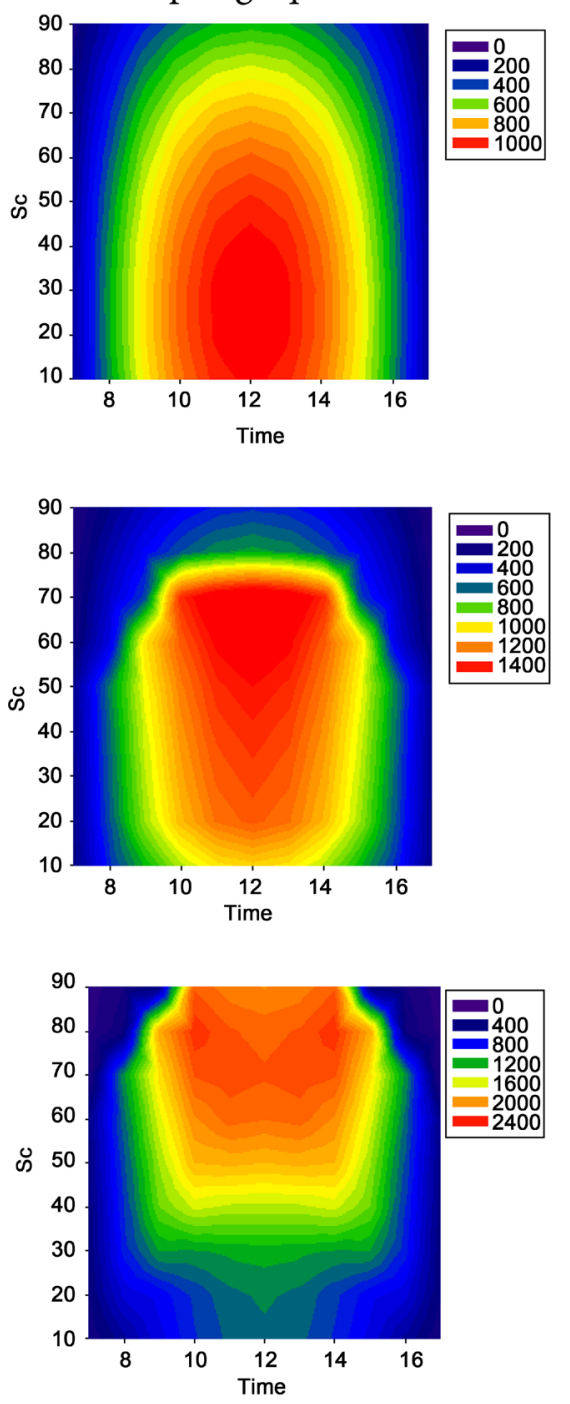

Summer solstice
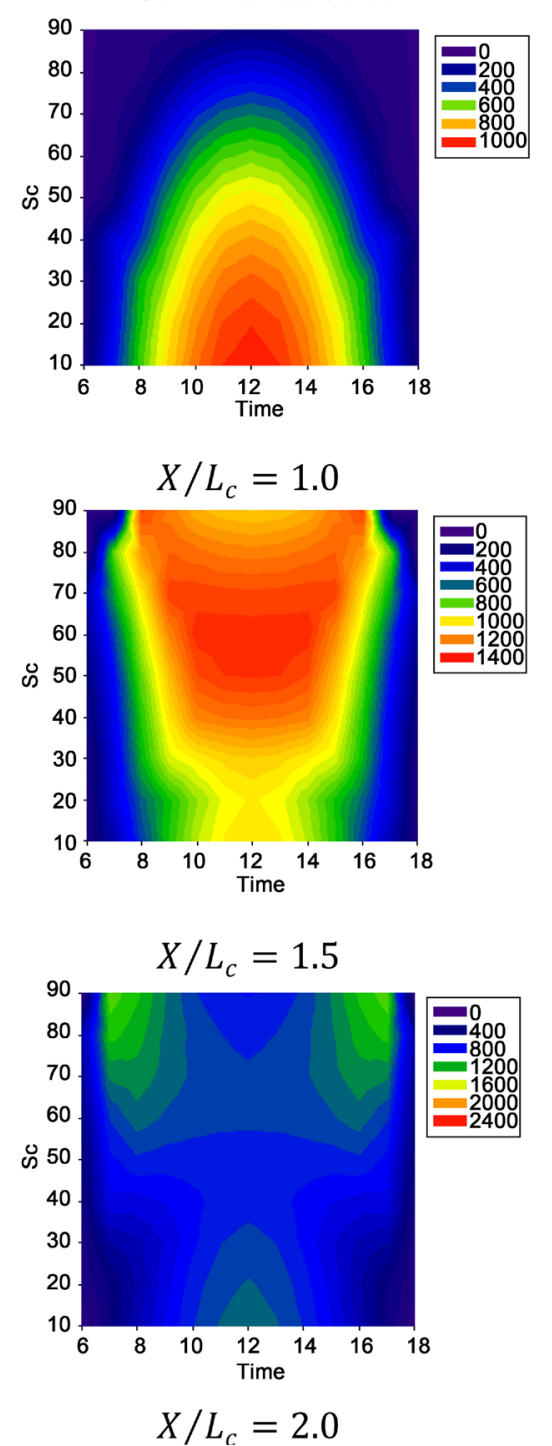

Winter solstice
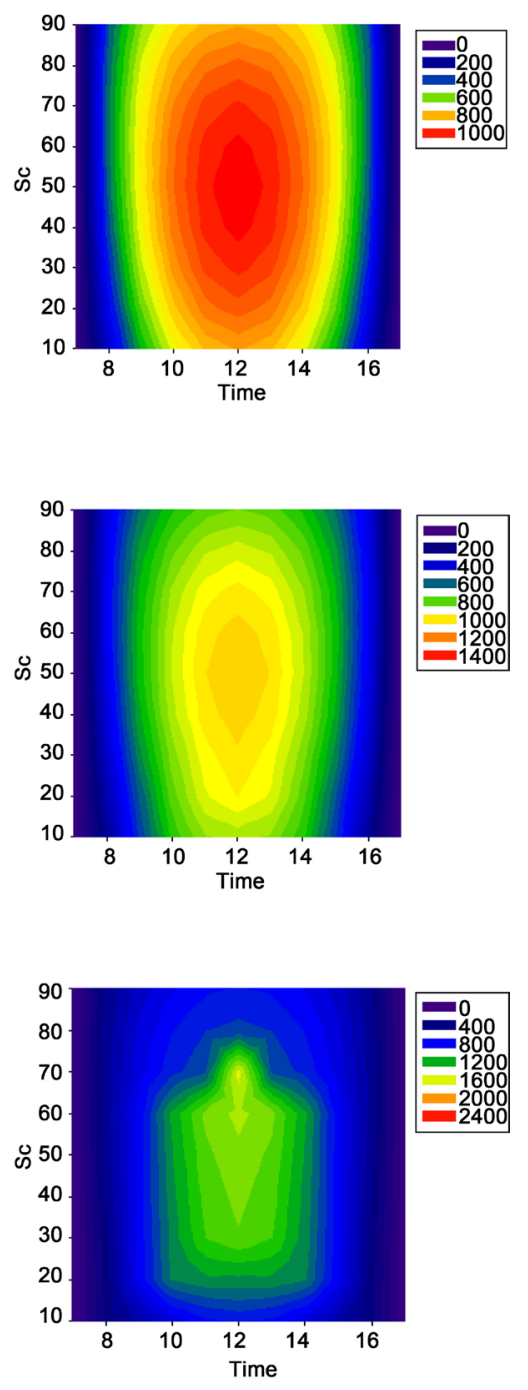

Figure 12. Hourly total solar radiation incident on a solar collector employed a flat reflector for spring equinox and for summer and winter solstices for various solar field design parameters. 


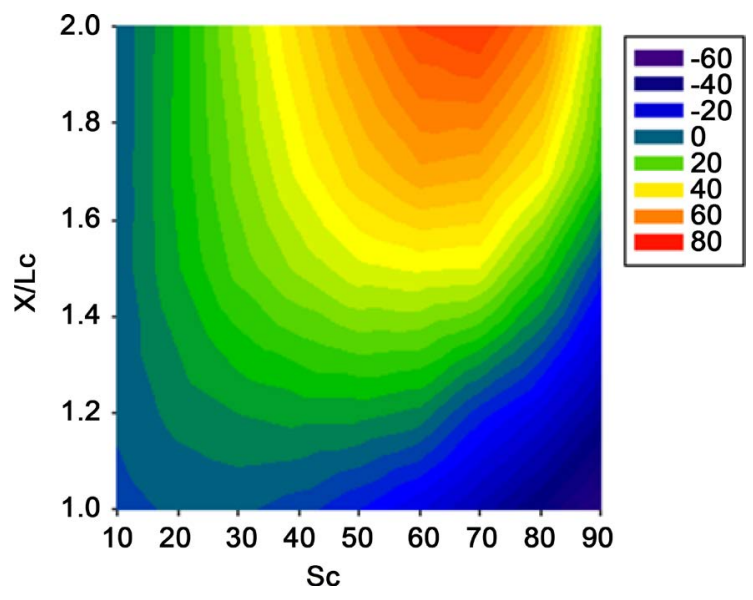

Figure 13. Percentage of solar energy collection improvement with respect to a single collector tilted to optimum tilt angle which equal to $30^{\circ}$ according to [12], for Brack El-ShatiLibya.

that occurred when the sun on the southern hemisphere during the winter solstice and also during the spring and fall equinoxes the opportunity of high concentration is large case (A, B and even D) and the effective height ratio is less than unity. While- in contrast- during the summer solstice, the sun is high in the sky dome and $\left(\theta_{i, r}^{t}\right)$ is small, the effective height ratio is relatively bigger and the reflected energy tended to fail outside of the collector's area (cases C and E), as it evident from Figure 11.

The annual enhancement percentage in solar energy collection with respect to a single surface tilted angle $30^{\circ}$ is depicted in Figure 13 for Brack El-Shati site. It is evidence from the Figure 13 that the optimum tilted angle of the collectors is increased with increasing the distance ratio; this relation can be established as a polynomial of fourth order with $R^{2}=1.0$ by using MSExcel program:

$$
S_{c .0 p t}=-225\left(\frac{X}{L_{c}}\right)^{4}+1448.3\left(\frac{X}{L_{c}}\right)^{3}-3417.8\left(\frac{X}{L_{c}}\right)^{2}+3534.9\left(\frac{X}{L_{c}}\right)-1316.5
$$

The obtained results show that, the annual solar energy collection increases by $72 \%$ for solar collector tilt angle of $70^{\circ}$ and decreases by $4 \%$ for collector tilt angle of $10^{\circ}$, when the distance separating the rows ratio $\left(\frac{X}{L_{c}}\right)$ is 2.0. While when the ratio $\left(\frac{X}{L_{c}}\right)$ equal to 1.5 . The maximum increase in solar energy collection was $32.7 \%$ for solar collector tilt angle of $60^{\circ}$ and decreases about $8.6 \%$ for solar collector tilt angle of $90^{\circ}$. The situation was dramatic for $\left(\frac{X}{L_{c}}\right)$ equal to 1.0 ; there is no improvement in the performance of the collector.

In the synoptic Figure 14 the improvement of solar radiation due to the plane reflector in solar field are depicted as a function of the solar field design parameters $\left(S_{C}\right.$ and $\left.X / L_{c}\right)$ and for many latitudes in the Northern hemisphere. The importance of the Figure 14 is, one able to determine the optimum solar collector 

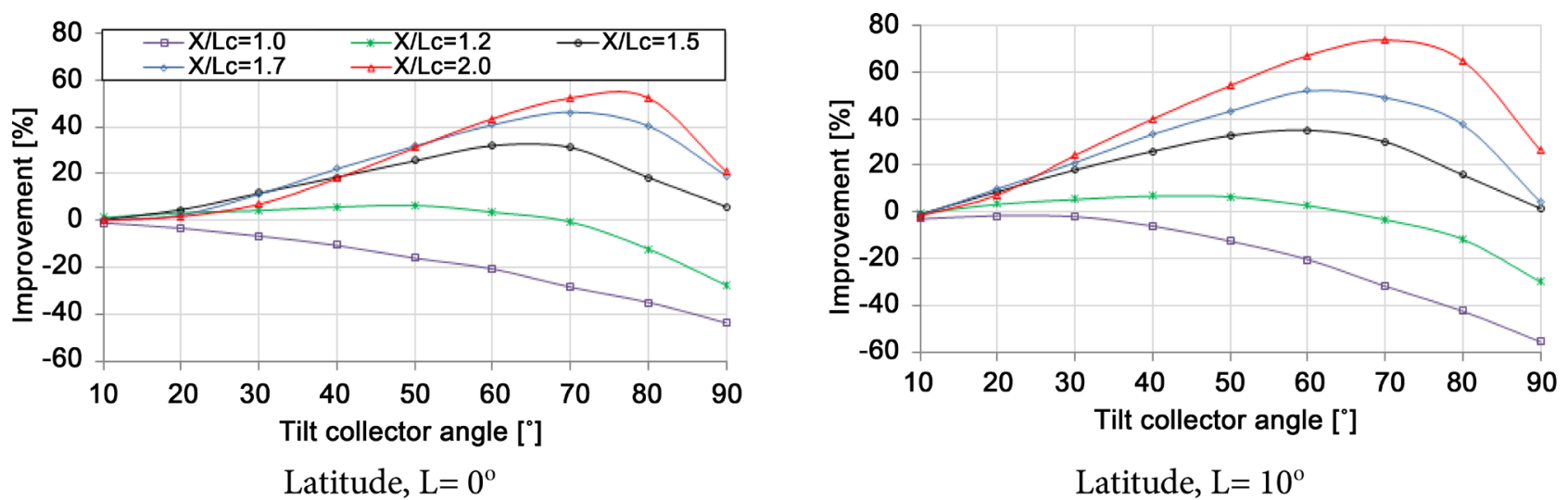

Latitude, $\mathrm{L}=10^{\circ}$
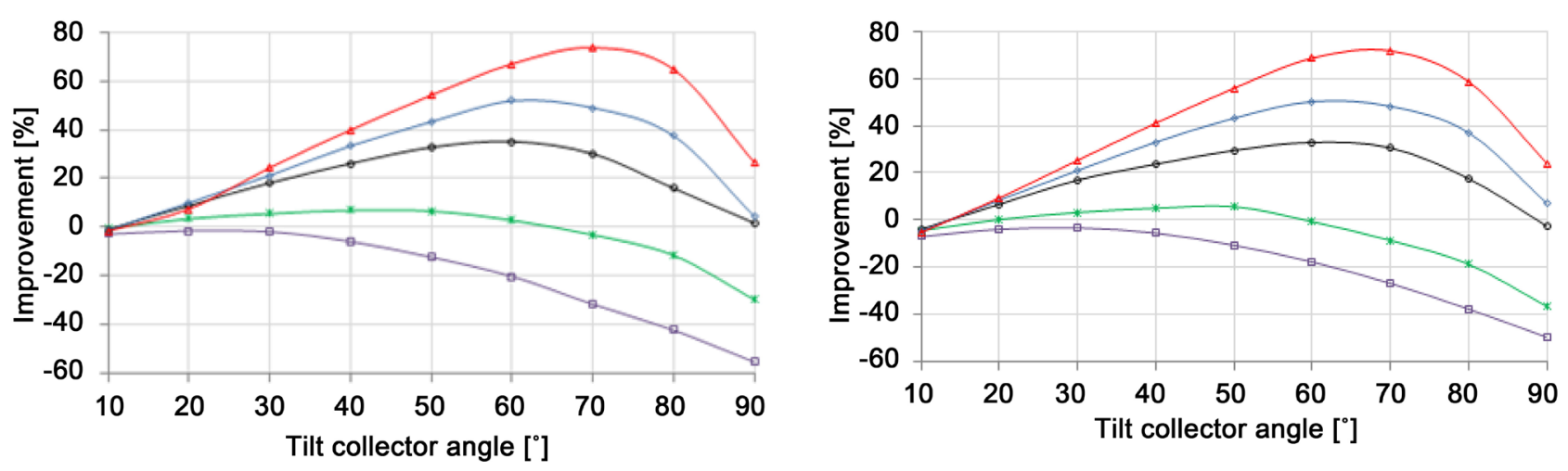

Latitude, $\mathrm{L}=20^{\circ}$

Latitude, $\mathrm{L}=30^{\circ}$
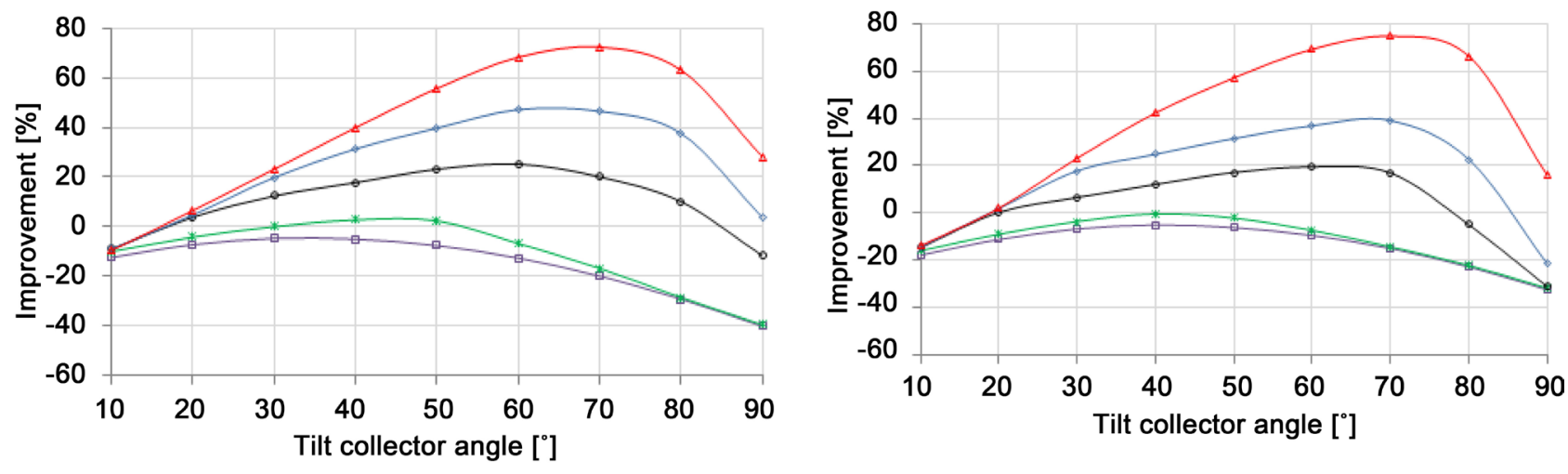

Latitude, $\mathrm{L}=40^{\circ}$

Latitude, $\mathrm{L}=50^{\circ}$

Figure 14. The obtained improvement of solar radiation vs. the solar field design parameters ( $S_{C}$ and $X / L_{c}$ ) for various latitudes on the Northern hemisphere.

tilted angle $\left(S_{C}\right)$ and the required distance ratio $\left(X / L_{c}\right)$ to achieve the intended percentage of improvement for any latitude. As it depicted in the Figure 14, the percentage improvement of solar radiation regarding to the latitude angle is virtually constant. The optimum collector tilt angle is relatively high for large distance ratio $\left(X / L_{c}\right)$ and tended to decrease with reduction in $\left(X / L_{c}\right)$. The obtained results show that, there is no improvement from the reflector when the distance ratio $X / L_{c}<1.2$, and we need an economic investigation to determine the benefits from the reflectors in solar fields. 


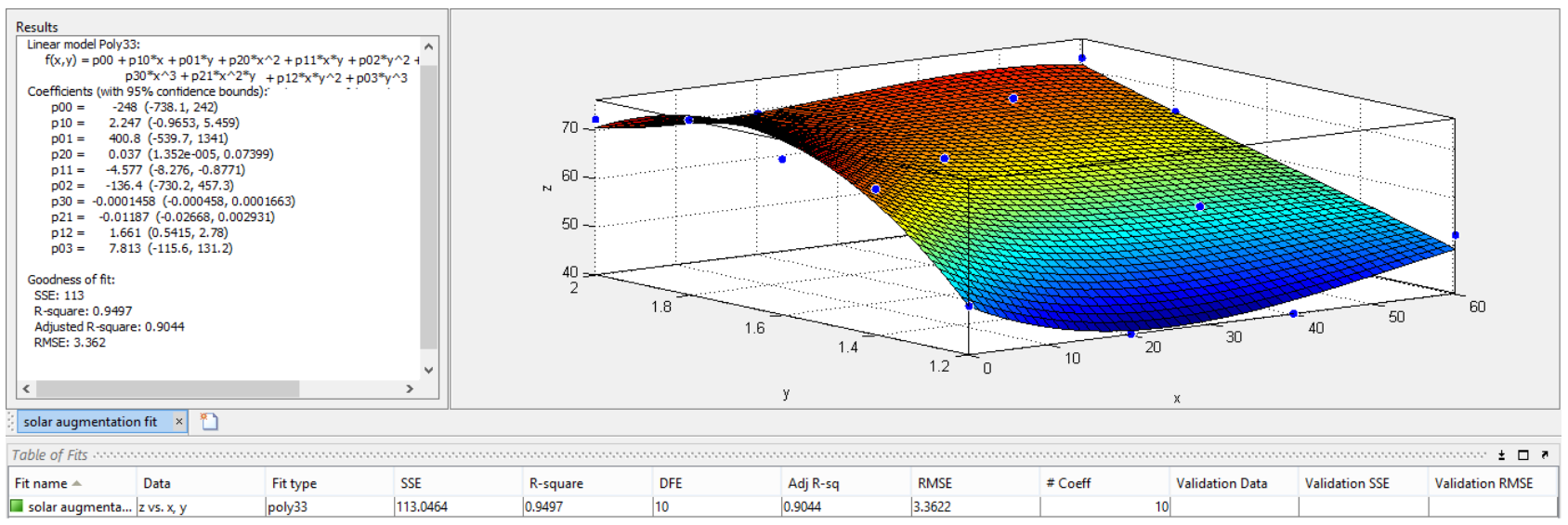

Figure 15. Z-axis presents the optimum collector tilted angle $S_{c . o p t}\left(L, X / L_{c}\right)$ vs. x-axis presents the latitude angle $(L)$ and y-axis presents the distance separating ratio $\left(X / L_{c}\right)$, and the polynomial that fits these three variables (table from the lift side).

The optimum tilted angle of the collector for any latitude angle on the Northern hemisphere associated to the solar field design parameters $\left(S_{C}\right.$ and $\left.X / L_{c}\right)$ is presented in Figure 15. A polynomial that fits these variables has been obtained by using MATLAB program and attached with the left side of Figure 15.

\section{Conclusions}

From our knowledge the solar radiation in stationary flat-solar fields is less than 5\% than that in a single solar collector. This reduction in solar radiation is mainly due to the variation of the view factors of the solar field with respect to a single solar collector. A further $5 \%$ reduction in solar energy will occur due to the shadowing. A significant augmentation of solar radiation received by the collector surface reached to $75 \%$ by using plane reflectors with a distance separating ratio $X / L_{c}=2.0$, and reached to $35 \%$ when $X / L_{c}=1.5$. The solar field design parameters $\left(S_{C}\right.$ and $\left.X / L_{c}\right)$ are playing crucial role in the augmentation process, in addition, the results show that the percentage improvement in solar radiation is independent on the latitude angle and the optimum solar collector tilt angle is-almost-for all latitudes are the same. Nonhomogeneous solar radiation distribution through the collector issues appears during the day which is presented a serious problem especially in the case of the PV panel solar field.

The results were obtained by this work significantly coincident with previous experimental results carried by others (such as [5] [7]), which makes us confident in recommending the use of the proposed approach for the design and optimization purposes of solar fields.

\section{Recommendations}

Further investigation must be followed to examine the effects of the inhomogeneous solar radiation distribution through the solar collector on the electrical performance of the PV solar fields. As it is shown in this work, the operation regime of the solar collector is almost located in the case " $\mathrm{A}$ " where $\frac{L_{c, e f f}}{L_{c}}<1.0$, the 
PV panels will suffer from the variation of solar radiation distribution. An economic study is recommended in order to determine the benefits of utilization of plane reflectors in solar fields of PV panels. Furthermore, the assumption that the output is proportional to irradiation will probably overestimate the output from PV modules with reflectors, since increased irradiation from the reflector increases the module temperature.

\section{References}

[1] Baccoli, R., Mastino, C., Innamorati, R., Serra, L., Curreli, S., Ghiani, E., Ricciu, R. and Marini, M. (2015) A Mathematical Model of a Solar Collector Augmented by a Flat Plate above Reflector: Optimum Inclination of Collector and Reflector. Energy Procedia, 81, 205-214. https://doi.org/10.1016/j.egypro.2015.12.085

[2] Ahmad, G. and Hussein, H. (2001) Comparative Study of PV Modules with and without a Tilted Plane Reflector. Energy Conversion \& Management, 42, 1327-1333. https://doi.org/10.1016/S0196-8904(00)00139-4

[3] Gelegenis, J., Axaopoulos, P., Misailidis, S., Giannakidis, G., Samarakou, M. and Bonaros, B. (2015) Feasibility for the Use of Flat Booster Reflectors in Various Photovoltaic. Installations International Journal of Renewable Energy Research, 5, 82-98.

[4] Pavlovic, Z.T. and Kostic', L. (2015) Variation of Reflected Radiation from All Reflectors of a Flat Plate Solar Collector during a Year. Energy, 80, 75-84. https://doi.org/10.1016/j.energy.2014.11.044

[5] Marko, P., Anne, M., Vincent, B., Michel, P., Martial, H. and Jordi, B. (2015) Experimental and Numerical Study of the Influence of String Mismatch on the Yield of PV Modules Augmented by Static Planar Reflectors. IEEE Journal of Photovoltaic, 5, 1-6.

[6] Bengt, P. and Bjorn, K. (1993) External Reflectors for Large Solar Collector Arrays, Simulation Model and Experimental Results. Solar Energy, 51, 327-337. https://doi.org/10.1016/0038-092X(93)90145-E

[7] Rob, W.A., Andrew, P. and Joshua, M.P. (2015) Photovoltaic System Performance Enhancement with Nontracking Planar Concentrators: Experimental Results and Bidirectional Reflectance Function (BDRF)-Based Modelling. IEEE Journal of Photovoltaics, 5, 1626-1635. https://doi.org/10.1109/JPHOTOV.2015.2478064

[8] Hiroshi, T. (2015) Theoretical Analysis of Solar Thermal Collector and Flat Plate Bottom Reflector with a Gap between Them. Energy Reports, 1, 80-88. https://doi.org/10.1016/j.egyr.2014.10.004

[9] Hay, J.E. and Davies, J.A. (1980) Calculation of the Solar Radiation Incident on a Inclined Surface. Proceedings of the First Canadian Solar Radiation Data Workshop, Toronto, April 17-19 1980, p 59.

[10] Duffie, J.A. and Beckman, W.A. (2013) Solar Engineering of Thermal Processes. 4th Edition, Wiley, New York. https://doi.org/10.1002/9781118671603

[11] Alsadi, S.Y. and Nassar Y.F. (2016) Correction of the ASHRAE Clear-Sky Model Parameters Based on Solar Radiation Measurements in the Arabic Countries. International Journal of Renewable Energy Technology Research, 5, 1-16.

[12] Alsadi, S.Y., Nassar, Y.F. and Amer, K.A. (2016) General Polynomial for Optimizing the Tilt Angle of Flat Solar Energy Harvesters Based on ASHRAE Clear Sky Model in Mid and High Latitudes. Energy and Power, 6, 29-38.

[13] Nassar, Y.F. and Alsadi, S.Y. (2016) View Factors of Flat Solar Collectors Array in Flat, Inclined, and Step-Like Solar Fields. Transactions of the ASME, 138, 1-8. 
Submit or recommend next manuscript to SCIRP and we will provide best service for you:

Accepting pre-submission inquiries through Email, Facebook, LinkedIn, Twitter, etc. A wide selection of journals (inclusive of 9 subjects, more than 200 journals)

Providing 24-hour high-quality service

User-friendly online submission system

Fair and swift peer-review system

Efficient typesetting and proofreading procedure

Display of the result of downloads and visits, as well as the number of cited articles Maximum dissemination of your research work

Submit your manuscript at: http://papersubmission.scirp.org/

Or contact sgre@scirp.org 